\title{
What is the benefit of screening for thyroid function in pregnant women in the detection of newly diagnosed thyropathies?
}

\author{
Hana Sarapatkovaa, Jan Sarapatka ${ }^{a}, Z^{2}$ denek Frysak ${ }^{b}$
}

\begin{abstract}
Background. Thyroid gland disturbances are the most common endocrine disorders in pregnancy. There are some particular recommendations for the investigation of women in risk groups, but no consensus guidelines for general screening exists at present in the Czech Republic.
\end{abstract}

Aim. The aim of our study was to determine whether universally conducted screening of pregnant women would reveal a significant number thyropathies.

Material and Methods. We examined 592 pregnant women for thyroid-stimulating hormone (TSH) and free thyroxine (fT4) levels and for autoantibodies against thyroperoxidase (antiTPO) in the $6^{\text {th }}-10^{\text {th }}$ week of their pregnancy.

Results. Levels of TSH, fT4 or antiTPO beyond laboratory reference limits were found by gynaecologists in 214 women $(36.1 \%)$ and 141 of whom (23.8\%) underwent endocrinological examination. In the women without known risk factors $(n=91)$ we found undiagnosed autoimmune thyroiditis in 20 cases $(22 \%)$ and in 7 cases $(7.7 \%)$ some degree of subclinical hypothyroidism was confirmed. Finally, $18(19.8 \%)$ women had hypothyroxinemia in the $1^{\text {st }}$ trimester (fT4 average $8.76 \mathrm{pmol} / \mathrm{L})$ with normal TSH levels. Altogether, a total of 45 women were succesfully identified $(49.5 \%$ of the endocrinologically examined group without risk factors, i.e. $7.6 \%$ of the whole screened group) who warranted monitoring. Of 73 women (12.3\%) who underwent screening and, despite recommendation, did not undergo endocrinological examination, there were 55 cases (9.3\% of the screened group) with positive levels of antiTPO and with elevation of TSH above the upper normal limit.

Conclusions. Of 592 women in the $6^{\text {th }}-10^{\text {th }}$ week of pregnancy who underwent thyropathy screening, we newly diagnosed $3.4 \%$ of women with autoimmune thyroiditis, $1.2 \%$ with subclinical hypothyroidism and $3 \%$ with hypotyroxinemia, for whom $\mathrm{n}$ o thyropathy risk factor had been evident. Thyropathies were identified in $7.6 \%$ of probands. We believe that our results support the importance of universal screening in pregnancy.

Key words: thyropathy, pregnancy, screening

Received: December 19, 2012; Accepted with revision: May 21, 2013; Available online: June 13, 2013

http://dx.doi.org/10.5507/bp.2013.041

${ }^{a}$ Endocrinology and Internal Outpatient Department, Fibichova 9, Olomouc, Czech Republic

${ }^{b}$ Department of Internal Medicine III - Nephrology, Rheumatology and Endocrinology, University Hospital Olomouc

Corresponding author: Hana Sarapatkova, e-mail: h.sarapatkova@atlas.cz

\section{INTRODUCTION}

The relationship between thyroid gland function, conception, course of pregnancy, and foetal development has been known for a long time. The most common thyroid gland dysfunction in pregnancy is hypothyroidism, the prevalence of which is estimated at $1.5-4.4 \%$ of pregnant women in the population ${ }^{1,2}$. As for the etiology an autoimmune inflammation of the thyroid gland, chronic thyroiditis is the most common cause. The other reason might be the inadequate supply of iodine and conditions after surgery on the thyroid gland or radioactive iodine treatment. Hypothyroidism is linked to reduced fertility in women $^{3}$. If a woman with hypothyroidism becomes pregnant then the lack of thyroid gland hormones leads during intrauterine development to irreversible damage to the foetus (failure of differentiation of nerve cells, inadequate central nervous system development and psychomotor function, increased risk of perinatal defects). The other threats are related to risk of premature birth, spontaneous abortion, placental abruption and post-natal bleeding, pre- eclampsia ${ }^{4,5}$. A recent study confirmed no improvement in the cognitive function of children born to women who were given thyroxine treatment on the basis of hypothyroidism detected through screening in the first trimester ${ }^{6}$.

Serious complication may also be a danger for euthyroid women with positive autoantibodies especially against thyroperoxidase ${ }^{7}$. A vast number of these women suffer from autoimmune thyroiditis (AIT). The thyroid gland is then unable to react to the increased demands for the production of thyroxine in pregnancy. Patients with autoimmune thyroiditis have twice or three times the risk of miscarriage in the $1^{\text {st }}$ trimester, which can be positively influenced by timely prescription of thyroxine . $^{8}$

A rather rare condition in pregnant women is hyperthyroidism: Both Graves - Basedow disease and autoimmune thyroiditis in its hyperfunctional form represent a complication in the course of pregnancy. The negative impact on the development of the foetus (foetal growth retardation, pre-eclampsia, miscarriage, premature birth) is evident. It is important to differentiate between this illness and simple TSH suppression or temporary thyrotoxicosis 
in pregnancy, which recedes spontaneously without treatment after the $14^{\text {th }}$ week of pregnancy ${ }^{2,9}$.

Despite the known complications of undiagnosed and untreated disorders of thyroid gland function for mothers and babies, there is still ongoing discussion about the extent of thyropathy screening. Universal examination of all women is not recommended ${ }^{9-11}$, the position supported by the American Thyroid Association (ATA) (ref. ${ }^{12}$ ).

On the other hand, there are studies which recommend universal screening ${ }^{13}$. One study conducted in 2010 confirmed twice the incidence of thyropathies in universal screening of pregnant women than in the case of examining women at risk ${ }^{2}$.

In our study we focused on the benefit of universal examination of pregnant women in the Olomouc region (Czech Republic) and women's interest in the option of examination.

\section{MATERIALS AND METHODS}

In cooperation with gynaecologists, blood samples were taken over a period of 2 years $(2010,2011)$ from pregnant women within prenatal screening in the $6^{\text {th }}-10^{\text {th }}$ week of pregnancy to determine the levels of TSH, fT4 and antiTPO. This was a total of 592 pregnant women who signed the written form to undergo examination and the processing of results.

All the pregnant women were advised to increase their dietary intake of iodine at the time of their first visit to the gynaecologist and they were offered supplements in the form of $100 \mu \mathrm{g}$ iodine per day or in the form of multivitamin with iodine for pregnant women. Commencement of iodine supplements varied, mostly after blood sampling.

Pregnant women, whose tests determined levels of TSH, fT4 or antiTPO outside the laboratory reference limits in any of the categories, were advised to undergo endocrinological examination. This applied to 214 (36.1\%) women, of which 141 (23.8\%) underwent examination. Sonographic examination of the thyroid gland was carried out, personal and family history of thyropathy was recorded along with personal history of other autoimmune illnesses. We retrospectively evaluated the available results of laboratory tests for women who did not undergo examination ( 73 women, $12.3 \%$ of the screened group).

In determining thyroid-stimulating hormone ( $\mathrm{TSH})$, free thyroxine (fT4) and autoantibody against thyroperoxidase (antiTPO) the Architect analyser was used (Abbott reagent) in the CMIA method (Chemiluminiscent Microparticle Immunoassay).

Laboratory reference limits for levels of TSH were 0.3 - $4.0 \mathrm{mU} / \mathrm{L}$, laboratory reference limits for fT4 were 9.55 - $23 \mathrm{pmol} / \mathrm{L}$, the laboratory normal limit for antiTPO was up to $5.61 \mathrm{kU} / \mathrm{L}$.

With regard to TSH and HCG interference in the first trimester we reassessed TSH results obtained by gynaecologists according to recommendations for pregnant women (TSH 0.06 or $0.03-3.67 \mathrm{mU} / \mathrm{L})\left(\right.$ ref. $\left.^{9,14}\right)$.

\section{RESULTS}

Of 592 women screened a total of 141 (23.8\%) pregnant women underwent endocrinological examination on the recommendation of a gynaecologist (Fig. 1). Of these, $8(5.8 \%)$ women had a personal history of thyropathy and a further $42(29.8 \%)$ had positive family history of thyroid gland illness. None of them had Type 1 diabetes mellitus or any other known autoimmune illness and 91 (64.5\%) of the pregnant women examined by an endocrinologist had no known thyropathy risk factors.

In the women with a positive family history (42 women) we found autoimmune thyroiditis with positive antiTPO and corresponding to sonographic findings in 13 (31\%) women. A further 5 (11.9\%) women had positive autoantibodies with normal sonographic findings. $14(33.3 \%)$ women were found to have pathological ultrasonography results, but we found no higher antiTPO levels. Of the women with a positive family history as a risk factor there were 32 (76.2\%) women requiring endocrinological observation, while 18 women $(42.9 \%)$ had positive antiTPO (Fig. 2).

In women with no known thyropathy risk factor (91 women), there were 20 (22\%) patients with newly diagnosed autoimmune thyroiditis - 14 eufunctional cases and another 6 subclinical hypothyroidism cases with path-

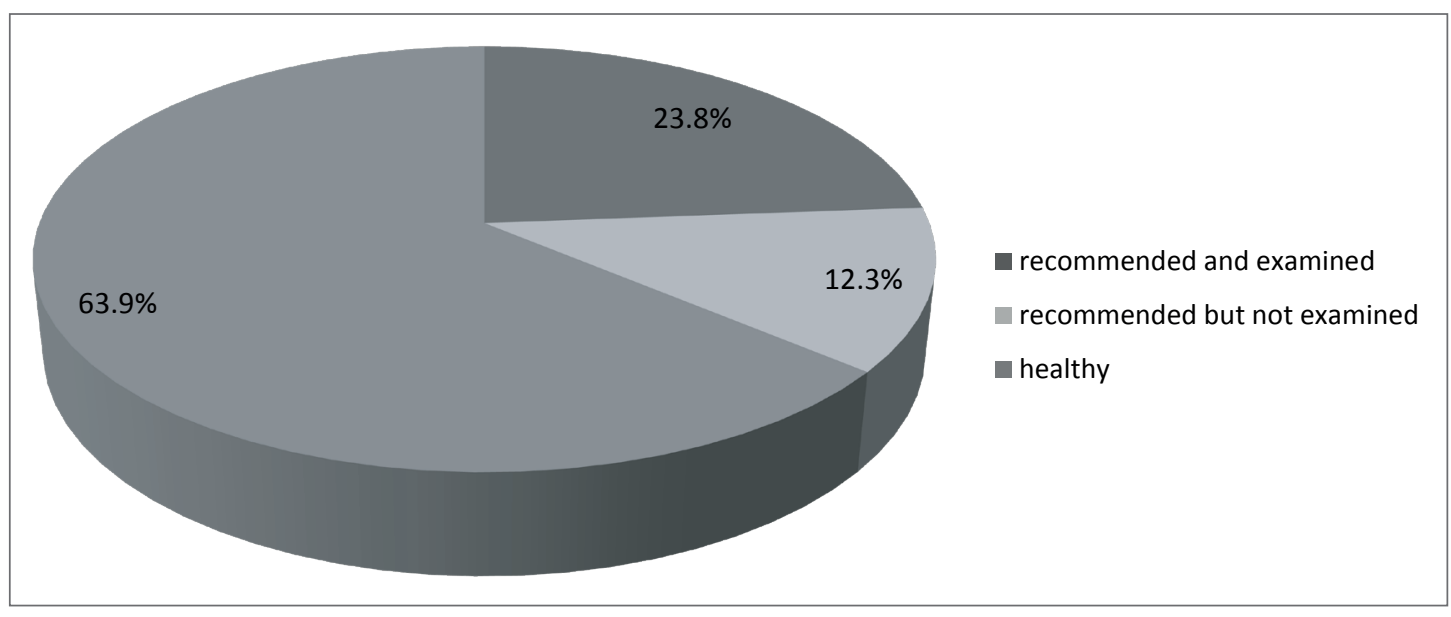

Fig. 1. Women who underwent screening $(n=592)$. 


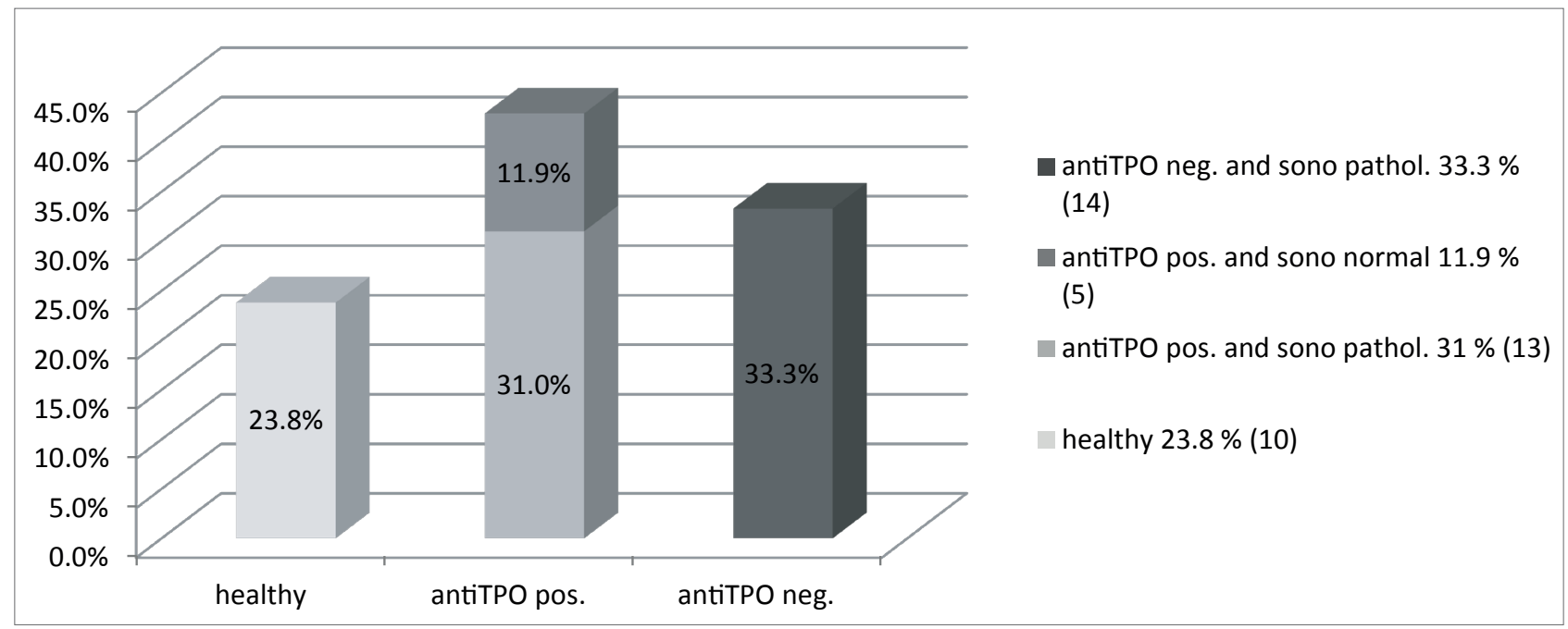

Fig. 2. Women with family history risk $(n=42)$.

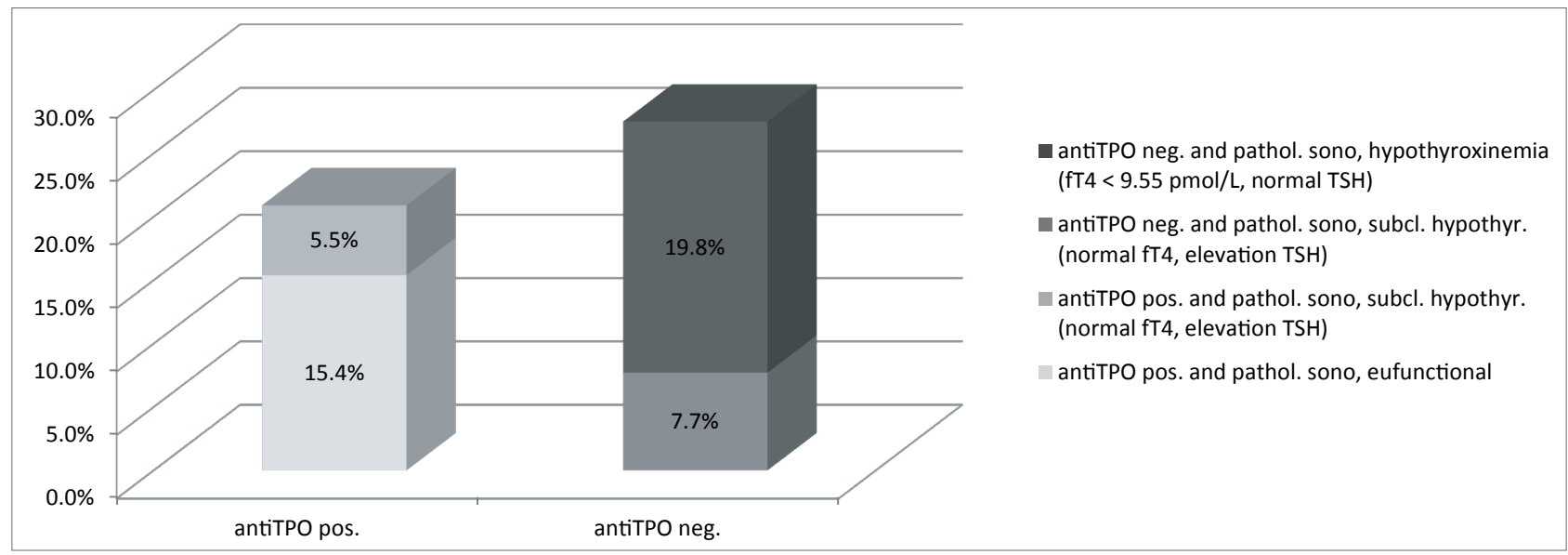

Fig. 3. Newly identified thyropathy in women with negative family history and with no known risk factors ( $\mathrm{n}=91)$. Reference range of TSH $0.06-3.67 \mathrm{mU} / \mathrm{L}$.

\section{TSH}

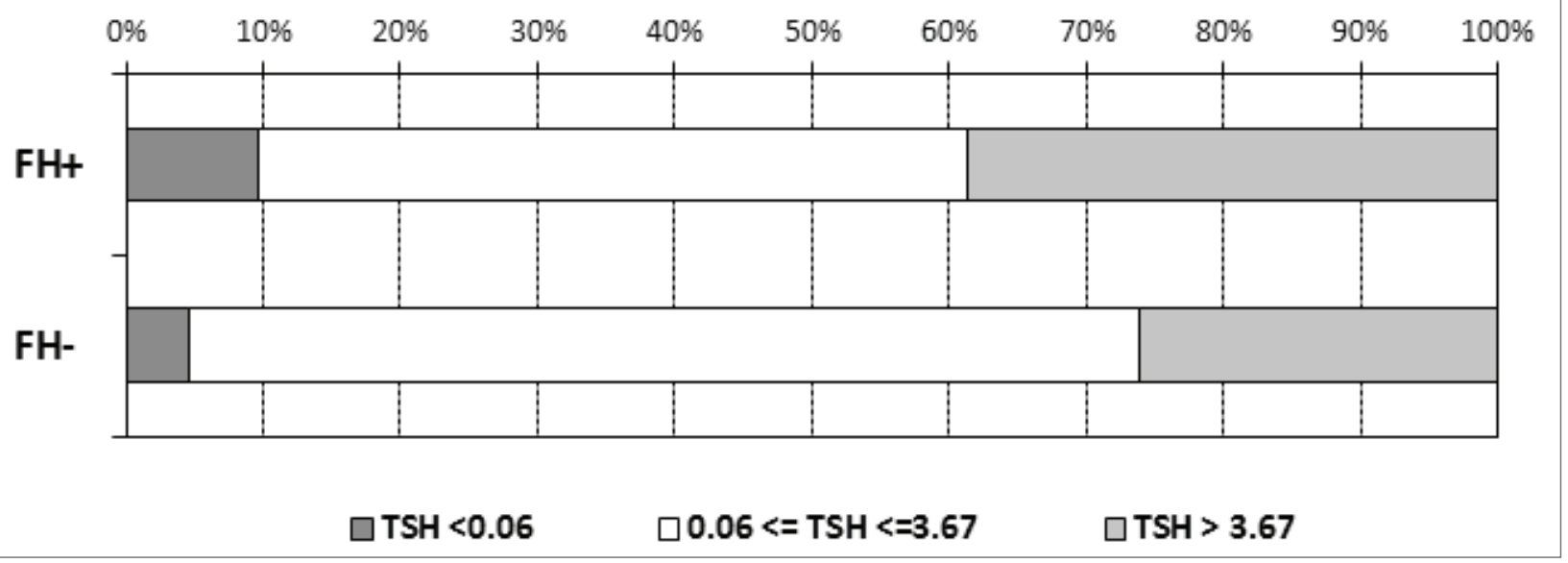

Fig. 4. Levels of TSH beyond recommended reference limits in women with positive (FH+) and negative (FH-) family history. 
ological findings on sonography and positive antiTPO at the same time. In 7 (7.7\%) women we found hypothyroidism and pathological sonography, but antiTPO was negative. 18 (19.8\%) women had hypothyroxinemia (range 7.8 - $9.52 \mathrm{pmol} / \mathrm{L}$, average $8.76 \mathrm{pmol} / \mathrm{L})$, negative antiTPO and pathological findings in sonography. All of these were considered to require further observation, i.e. a total of 45 women with newly identified thyropathy $(49.5 \%$ of women undergoing endocrinological examination, i.e. $7.6 \%$ of the whole screened group), which is practically half of the women without known risk who were referred to an endocrinologist (Fig. 3).

With regard to TSH and $\mathrm{HCG}$ interference in the first trimester we reassessed TSH results obtained by gynaecologists according to recommendations for pregnant women (TSH 0.06 or 0.03 - $3.67 \mathrm{mU} / \mathrm{L})$ ( ref. $^{7,9}$ ). In 11 women ( $1.9 \%$ of the screened group) the TSH levels were within recommended limits, but they showed an indication of autoimmune thyroiditis with positive autoantibodies against thyroperoxidase and the image of thyroiditis on the sonograph. These women would not have been diagnosed without examination of antiTPO. We did not diagnose thyrotoxicosis even once (Fig. 4).

In the women examined within the screening period by a gynaecologist, but who did not take up the option of endocrinological examination (73 women i. e. $34.1 \%$ of women for whom endocrinological examination was recommended and $12.3 \%$ of the whole screened group), 27 women were subsequently found to be antiTPO positive and 21 women were found to have TSH above the upper limit of norms. A further 7 probands had concurrently increased levels of both antiTPO and TSH that corresponded to subclinical hypothyroidism. These 55 women $(9.3 \%$ of the whole screened group) should be observed and even treated further, the risk factors for this group are not known.

In women who underwent endocrinological examination we found a total of 38 women $(28.6 \%)$ with positive autoantibodies against thyroperoxidase. In the whole group of women who underwent screening 65 women (11\%) had positive antiTPO.

\section{DISCUSSION}

In 2004 examination was recommended for pregnant women and women planning pregnancy with the aim of preventing the unfavourable result of unrecognised subclinical hypothyroidism ${ }^{15}$. In 2007 a recommendation was drawn up on the basis of consensus of thyroid associations $^{9}$. The recommendation deals with illness of the thyroid gland in pregnancy, its detection and treatment, ideally also setting preconception diagnosis. Examination of TSH is recommended, possibly fT4 and antiTPO for patients in risk groups (Table 1). Consensus guidelines for thyroid disorder screening have been published in the Czech Republic ${ }^{16}$.

In our opinion, of the stated risk factors it is easy to identify women with a personal history of thyropathy and with irradiation of head and neck. Information on family
Table 1. Risk groups of women advised to undergo examination of thyroid function in pregnancy.

1. Women with a personal history of thyropathy or with previous irradiation of head and neck

2. Women with a family history of thyroid gland illness

3. Women with clinically known illness, goitre or symptoms

4. Women with positive antiTPO or antiTBG autoantibodies

5. Women with Type $1 \mathrm{DM}$ or other autoimmune illness

6. Women examined for sterility within examination protocol

Adapted according to Abalovich et al. 2007 (ref. ${ }^{9}$ ).

history is more problematic - we repeatedly came across data on negative family history only for the patient to change the original information during a check-up after the examination. Clinical symptoms of thyroid gland illness - tiredness, inefficiency, sleepiness etc. are not typical, and coincide with general symptoms of pregnancy. This is also given by the fact that, in the Czech Republic where iodine intake is sufficient, we are dealing with subclinical forms of hypothyroidism ${ }^{17}$. In our experience, palpable goitres are uncommon in young women, evaluation of the size of the thyroid gland without sonographic examination is often problematic. Autoantibodies (antiTPO and antiTBG) are specifically determined in women with suspected thyropathy.

In our study group we found 50 women $(8.4 \%)$ in risk groups - 8 women with personal history of thyropathy, a further 42 women had positive family history of thyropathy. The high percentage of women with diagnosed thyropathy with positive family history indicates the importance of monitoring this case-history information, even if it is not always completely valid information.

Through universally conducted examination in the group of women with no known risk of thyropathy we found 45 women $(7.6 \%)$ who require endocrinological treatment.

Even in this risky period, where we would expect greater interest in good health and a successful course of pregnancy, there were a total of 55 women $(9.3 \%$ of the whole screened group) whose screening tests indicated pathologies, but who did not come for endocrinological examination despite this being recommended.

It is impossible to speak of the risk of these women who should be monitored and treated. They run the risk of complications due to increased antiTPO level, practically half of them have subclinical hypothyroidism and run the risk of postnatal thyroiditis and hypothyroidism ${ }^{18}$.

The incidence of positive autoantibodies against thyroperoxidase was high among women with positive family history, overall we detected them in $10.1 \%$ of the women, which corresponds with published data ${ }^{8,14}$.

Our observation found $7.6 \%$ newly diagnosed thyropathy in women with no risk factor, which corresponds with a pilot study in $\mathrm{CZ}$ ( ref. $^{19}$ ). Another study showed that if only patients in risk groups are examined about a third 
of women with hypothyroidism will not be detected ${ }^{20}$. A similar conclusion was reached by a further study - here as much as $55 \%$ of women with thyropathy, who had no risk factors, would not be examined ${ }^{2,13}$.

Universally conducted screening revealed 132 women, i.e. $22.3 \%$ of all women examined, who should be monitored and treated for thyropathy. It can be stated that, from every 100 women without risk factors who are screened, we would find almost 17 women with newly detected thyropathy. In terms of the effectiveness of the expenses incurred we consider this approach to be appropriate $^{16,21}$.

\section{CONCLUSIONS}

On the basis of the results of our study we believe that $7.6 \%$ newly diagnosed thyropathy in women with no known risk factor is a sound argument for introduction of simple universal screening of pregnant women. We believe that evaluation of TSH and fT4 levels in the $5^{\text {th }}-10^{\text {th }}$ week of pregnancy is necessary to determine thyroid function. Without evaluation of antiTPO levels $1.9 \%$ of autoimmune thyroiditis with pathological sonography could not be diagnosed in our study. Attention should be given to another $12.3 \%$ of women in our study who did not undergo endocrinological examination despite recommendation and $9.3 \%$ who should be observed and treated further, the risk factors for this group are not known.

It is essential to improve cooperation between gynaecologists, endocrinologists and GPs. It is also essential that the public is better informed on the importance of examination.

\section{ACKNOWLEDGEMENTS}

The authors of this article wish to thank numerous doctors, and especially Yvona Hrckova, Monika Coufalova, Drahomira Manakova, Ales Skrivanek, Pavel Turcan and Ivana Weinbergova, for their assistance and cooperation.

\section{CONFLICT OF INTEREST STATEMENT}

Author's conflict of interest disclosure: None declared.

\section{REFERENCES}

1. Lazarus JH, Premawardhana LDKE. Screening for thyroid disease in pregnancy. Journal of Clinical Patology 2005;58:449-52.

2. Horacek J, Spitalnikova S, Dlabalova B, Malirva E, Vizda J, Svilias I, Cepkova J, McGrath C, Maly J. Universal screening detects two-times more thyroid disorders in early pregnancy than targeted high-risk case finding. European Journal of Endocrinology 2010;163:645-50.

3. Poppe K, Velkeniers B, Glinoer D. The role of thyroid autoimmunity in fertility and pregnancy. Nature Clinical Practice Endocrinology and Metabolism 2008;4:394-405.
4. Morreale de Escobar G, Escobar F. Maternal thyroid hormones early in pregnancy and fetal brain development. Best practice and research Clinical Endocrinology Metabolism 2004;18:225-48.

5. Benhadi N, Wiersinga WM, Reitsma JB, Vrijkotte TGM, Bonsel GJ. Higher maternal TSH levels in pregnancy are associated with increased risk for miscarriage, fetal or neonatal death. Eur J Endocrinol 2009;160:985-91.

6. Lazarus JH, Bestwick JP, Channon S, Paradice R, Maina A, Rees R, Chiusano E, John R, Guaraldo V, George LM, Perona M, Dall'Amico $D$, Parkes AB, Joomun $M$, Wald NJ. Antenatal thyroid screening and childhood cognitive function. N Engl J Med 2012;366(6):493-501.

7. Potluková E, Jiskra J, Telička Z, Bartáková J, Springer D. Pozitivita protilátek proti tyreoidální peroxidáze u eutyreózních těhotných žen jako rizikový faktor pozdějšího rozvoje dystyreózy. Diabetes, Metabolismus, Endokrinologie, Výživa 2011;14:27-32.

8. Negro R, Formoso G, Mangieri T, Pezzarossa A, Dazzi D, Hassan H. Levothyroxine treatment in euthyroid pregnant women with autoimmune thyroid disease: effect on obstetrical complications. Journal of Clinical Endocrinology and Metabolism, 2006;91:2587-91.

9. Abalovich M, Amino N, Barbour LA, Cobin RH, De Groot LJ, Glinoer D, Mandel SJ, Stagnaro-Green A. Management of thyroid dysfunction during pregnancy and postpartum: an Endocrine Society clinical practice guideline. Journal of Clinical Endocrinology and Metabolism 2007;92(8 Suppl):S1-47.

10. Negro R, Schwartz A, Gismondi R, Tinelli A, Mangieri T, StagnaroGreen A. Universal screening versus case finding for detection and treatment of thyroid hormonal dysfunction during pregnancy. Journal of Clinical Endocrinology and Metabolism 2010;95:1699-707.

11. Lazarus JH. Screening for Thyroid Dysfunction in Pregnancy: Is It Worthwhile? J Thyroid Res 2011;2011:397012. doi: $10.4061 / 2011 / 397012$

12. Stagnaro-Green A, Abalovich $M$, Alexander E, Azizi F, Mestman J, Negro R, Nixon A, Parce EN, Soldin OP, Sullivan S, Wiersinga W. Guidelines of the American Thyroid Association for the diagnosis and management of thyroid disease during pregnancy and postpartum. Thyroid 2011;21:1-45.

13. Potlukova E, Jiskra J, Telicka Z, Springer D, Limanova Z. Universal Screening for Thyroid Disorders in Pregnancy: Experience of the Czech Republic, A New Look at Hypothyroidism, Drahomira Springer (Ed.) 2012; InTech, Available from: http://www.intechopen.com/ books/a-new-look-at-hypothyroidism/universal-screening-for-thyroid-disorders-in-pregnancy-experience-of-the-czech-republic

14. Springer D, Zima T, Limanova Z. Reference intervals in evaluation of maternal thyroid function during the first trimester of pregnancy. European Journal of Endocrinology 2009;160:791-97.

15. Surks MI, Ortiz E, Daniels GH, Sawin CT, Col NF, Cobin RH, Franklyn JA, Hershman JM, Burman KD, Denke MA,Gorman C, Cooper RS, Weissman NJ. Subclinical thyroid disease: scientific review and guidelines for diagnosis and management. Journal of the American Medical Association 2004;291:228-38.

16. Horáček J, Jiskra J, Límanová Z, Springer D, Zamrazil V. Doporučení pro diagnostiku a léčbu onemocnění štítné žlázy v těhotenství a pro ženy s poruchou fertility. Diabetes, Metabolismus, Endokrinologie, Výživa 2013;16(1):38-61.

17. Zamrazil V, Bilek R, Cerovska J and Delange F. The elimination of iodine deficiency in the Czech Republic: the steps toward success. Thyroid 2004; 14:49-56.

18. Premawardhana LDKE, Parkes AB, Ammari F, John R, Darke C, Adams H, Lazarus JH. Postpartum thyroiditis and long-term thyroid status: prognostic influence of thyroid peroxidase antibodies and ultrasound echogenicity. Journal of Clinical Endocrinology and Metabolism 2000;85:71-5.

19. Límanová Z, Springer D. Současné zkušenosti s vyšetřováním tyreopatií v graviditě - výsledky pilotního projektu. Čas Lék čes 2011;150:389-93.

20. Vaidya B, Anthony S, Bilous M, Shields B, Hutchison S and Bilous R. Detection of thyroid dysfunction in early pregnancy: universal screening or targeted high-risk case finding? The Journal of Clinical Endocrinology and Metabolism 2007;92(1):203-7.

21. Dosiou C, Sanders GD, Araki SS, Crapo LM. Screening pregnant women for autoimmune thyroid disease: a cost-effectiveness analysis. European Journal of Endocrinology 2008;158:841-51. 